\title{
Birger Sevaldson
}

\section{Discussions \& Movements in Design Research}

\author{
A systems approach to practice research in design
}

\begin{abstract}
The main approach of this paper is to look at design research from a systems-oriented perspective. This implies that design research is understood as a dynamic and emergent field of interrelated or contradicting thoughts, concepts and ideas. The first three sections of this paper draw cross-sections into the emerging richness in design research as it matures as a genuine mode of knowledge production. They address some of the positions, concepts, and discussions going on in the field, arguing that practice research in design is the most central. The current state is discussed and the relation between design research and other modes of knowledge production are looked at. A main tendency seems to be that design research is moving towards greater complexity both in issues and approaches and that Research by Design is becoming ever more central. Research by Design emphasizes insider perspectives, $a$ generative approach, operates in rich and multiple layers and relates to real life contexts. The output is new communicable knowledge that is only found within design practice. The next two sections of the paper discuss the various possible relations between design practice and reflection. These span from distant perspectives where design practice is observed by outsider researchers, looking at practice retrospectively or contemporarily as in case studies, to participatory research and insider perspectives where the designer-researcher uses his or her own practice as a means for investigation and a bases and subject for reflection and knowledge production. The last section proposes the critical application of multiple perspectives, methods and media in composite approaches to design research. This analysis does not claim to provide a complete picture, but it suggests a method of looking at the field of design research in both a more holistic and more specific way. This could be helpful to position the individual design researchers approach in the complex landscape of design research. Arguing that 'traditional sciences' are very complex and manifold, design research is in itself a very complex, if not one of the most complex field of knowledge production. The paper claims that such a complexity demands an equally rich repertoire of interrelated methods and positions.
\end{abstract}

Keywords: design research, research by design, practice based research.

\section{Introduction}

After many years the concepts and methods for design research are still in a state of development. To move forward, I suggest that we need to do two seemingly contradicting things:

1) We need to see the whole in design research. Richard Buchanan (1992) stated early that there is no single definition that adequately covers design. Equally, design research approaches and methods are manifold and complex, a fact that frequently has been overlooked when conceptions of rigour and traditional scientific methods have been discussed and simplistic models have been suggested. A systems perspective on the field of design research provides a holistic and dynamic view that looks at design research as a complex field on the move where new ideas and positions are formed, where there are ideological contradictions and where new patterns of research practice emerge. The systems perspectives that form the backdrop of this analysis stems from the Systems Approach as described by C.West Churchman as a legacy from World War II and Operations Research developing 
systems thinking as a means of planning and action (Churchman, 1979). It is also inspired by Soft Systems Methodology as defined by Checkland (2000), Systems Architecting as defined by Maier and Rechtin (2000), people like Donella H. Meadows (2008) who emphasise an intuitive and flexible approach to systems thinking, and Hinte and Tooren (2008) describing of a soft designerly version of systems engineering. The author has developed the concept of Systems Oriented Design, developing design proprietary approaches and skills for systems thinking. The central issues are to emphasise the patterns of the field of relations rather than the hierarchical ordering of the systems entities and their borders (Sevaldson, 2009).

2) We need to become specific and detailed in describing the relations between the items found in this field. A systems approach to design research also involves looking at the details in the field and how they are related. This is obviously an enormous task and this paper only provides a draft. The task of this draft, however, is to suggest a way to describe and differentiate these emergent models. This is achieved by describing the relations between practice and research, between making and reflection and between implicit and explicit knowledge. Other design researchers realise that it is necessary to go in this direction. Mattelmäki and Mathews (2009) give six different examples of possible relations between research and design or art practice. The way forward is to become more explicit and exact in defining the multiple and rich landscapes of design research. The aim is not to narrow down the field and arrive at a simplified consensus but to open up the field and give design researchers access to a rich repertoire of possible research perspectives.

An important aspect in this paper is to relax the relation to other 'traditional' sciences so as to position design research in a larger academic context. To achieve this, we need to meet four requirements:

- to regard the 'traditional' sciences as non-threatening but very valuable sources for inspiration in building a design research repertoire. This is necessary since design research can be seen as defensive and other disciplines as patronising. By clarifying the diverse modes and positions found in design research we could avoid evaluating them according to irrelevant analytical perspectives.

- to realise that these so-called traditional sciences are not uniform nor traditional but differentiated, innovative and on the move.

- to be specific not only towards our own discourse but also to compare it with others. Knowing the specificities of design research, is needed to distinguish when we can learn from others and when we need to develop proprietary concepts and methods from which others can learn.

- to specify what part of design research produces unique knowledge not found in other domains. This unique core of design research is found in Research by Design, where the design researcher is also a practitioner and whose investigations are conducted within a 'first person perspective' combined with a reflexive mode of inquiry that helps make design knowledge explicit. In this mode of research, there is great potential for both reflection and knowledge production, but also for the further development of practice. Such a synergy has been reported e.g. by Steven Scrivener (2004).

When these four requirements are met, we have formed the base needed to describe the different possible modes of research in a specific manner. This is achieved by focussing on the relation between design as a practice and theorising in design. Practice and reflection form the unique mode of designerly knowledge production. By starting to describe these relations, 
we also reach a state were these relations can be redefined according to our own needs. We then reach a state of designing design research.

When we have established a basic overview of the complex field of design research seen from a systems perspective, we are able to distinguish between many possible modes of conducting such research. These modes are defined by their differing relations between practice and reflection, as I will show in the last part of this paper.

The main method used in this paper to draw a complex picture and to analyse the relations in the field of design research is to cut three cross-sections on different scales through this diverse landscape. Cutting cross-sections implies leaving the larger volume of the subject untouched. It is therefore important to keep in mind the incompleteness of the proposed concepts. Starting with a brief summary of existing and inherent definitions, we then continue by addressing some of the current discussions in design research where movements and contradictions are uncovered with a special emphasis on the relation between research by design and what is frequently called 'traditional sciences'. The last cross-section looks at world views found in design research, going through some of the models found. Then I discuss how to analyse the relations between practice and reflection and suggest some variables to use in this discussion. Lastly, I attempt to become specific in applying these variables to distinguish between a series of possible relations.

\section{Cross-section 1: Definitions}

In this section I intend to clarify some of the many terms and notions of practice research and design research we find. This might seem somewhat banal at first glance. However, many different terms and labels are in use without being used consistently. For example, the term Practice-led Research is introduced by the AHRC Research Review, Practice-Led Research in Art, Design and Architecture (Rust, Mottram, \& Till, 2007). In this case, the term is used exclusively for design and architecture related research, while the term itself indicates a much wider possible application.

In this list I start with the most globally applicable term, Practice Research, which spans across many domains and perspectives. The term is applicable to all profession-based research that looks at or involves in practice. We find many kinds of research approaches within practice research. Towards the end of the list I try to sort out the definitions that are specific for the field of design.

\section{General definitions for practice-related research}

- Practice Research: A global definition that includes all different modes of research involving all kinds of practices. The term is not well defined but from the denotation of the term I derive the definition as a global term embracing all practice related research.

- Practice-based research: Used in clinical research (American Academy of Family Physicians, 2009). Probably used as a quite wide definition where different relations between research and practice are played out. Frequently used in design discourse.

- Practice-as-research: Used in the arts, mainly to define the generative and explorative aspects of the art practice. Practice-as-research claims that certain practices are research by them selves, without the requirement of a verbally expressed reflection, while others claim that you need an additional externalised format (text, scientific publication) to define these practices as research. 
- Research-based practice: Practice strongly related to a research field where the practice seeks to implement the research findings. An example in the design field is InformeDesign (2009). This is a collaboration between the University of Minnesota and the American Association of Interior Designers (ASID) (Guerin \& Dohr, 2009; InformDesign). The term is also used in other fields, e.g. education.

- Practice through research: A form of practice that connects to research, e.g. in design one can imagine designers being part of research and development groups. Results in new practices. Gets commisions from research and development. The phrase is most often used as a way to describe improvement of practice through research (Kottke, 2008). In this interpretation it is very similar to research-based practice.

- Practice-led research: Definition from AHRC Reseach Review, Practice-Led report: "Research in which the professional and/or creative practices of art, design or architecture play an instrumental part in an inquiry" (Rust et al., 2007: 11). As mentioned, this definition is somewhat unsatisfying because one could think of other practices than art, design and architecture applying the same or similar perspectives, approaches and methods. It also can apply to many different modes so it is synonymous with Practice Research.

\section{Definitions specific for the field of design}

- Design Research: Global definition of all design related research. This includes both theoretical and practice related studies plus general design studies.

- Research INTO Design: Inquiry that looks at design from a distant perspective. Part of Frayling's concepts Research INTO, FOR and THROUGH design discussed later. Also called Research ABOUT Design.

- Research FOR Design: Research that serves design and is subservient to design.

- Research THROUGH Design: Any research were the design practice is central in generating knowledge. Can also address external tasks given by others.

- Research by Design: A special research mode where the explorative, generative and innovative aspects of design are engaged and aligned in a systematic research inquiry. The definition distinguishes Design practices in research from other practices. It implies that the design practices by themselves have an inherent element of investigation, innovation and knowledge generation, as opposed to e.g. nursing practices. But it also indicates that these practices need to be complemented with a special dimension of reflection to qualify as research. Addresses mostly internal aims emerging from within design practice. Unfortunately, the term has been taken by some management and strategy consultancies, as www.researchbydesign.com.au (Research by design, 2009) and www.researchbydesign.co.uk (Research by design Ltd., 2009). But an increasing number of design and architectural schools are using the term. Design research institutions should actively claim it and use it instead of using less precise terms like practice-led research. To my mind, this is the most appropriate term to describe the most central mode of research in the design fields (Free University of Bozen-Bolzano, 2007, Sint-Lucas School of Architecture, 2009). 
- Design-oriented research and research-oriented design: This is a distinction suggested by Daniel Fallman. (See immediately below).

- Design-oriented research: "Research is the area and design the means....... seeks to produce new knowledge by involving typical design activities in the research process" (Fallmann, 2007: 197).

- Research-oriented Design: "Design is the area and research the means.... ...the creation of new products and in that process, answering to the problems and realworld obstacles that are faced in that process, is the primary objective" (Fallmann, 2007: 198).

\section{Cross-section 2: Current discussions \& contradictions in design research}

To draw a just picture of the developments and movements in design research is a task that exceeds the limits of this paper, not to mention the bigger picture including the half a century of reflections upon design methods and theories that have passed. For such an overview one could refer to e.g. Nigel Cross' introduction to an issue of Design Studies (Cross, 2007b). The short cross-section presented here aims at looking especially at practice research in design. The relation between design practice and research has been discussed for some years now.

With some exceptions there have been few attempts to move forward by becoming more specific and explicitly describing different possible approaches as part of a bigger picture. I would claim that many of the concepts found in design research are quite general and unspecific and also unclear. In this section I will go through some of these general concepts and, in the end, point towards discussions that are more specific and that indicate the building of a more consistent, rich, and detailed repertoire for design research. Finally, I will show that there is a movement towards a more inclusive and multi-layered and systemsoriented interpretation of practices as modes of knowledge production.

Archer and Frayling advanced the above-mentioned and widely used three modes of design research (Archer, 1995; Frayling, 1993; Rust et al., 2007):

- Research FOR practice, where research aims are subservient to practice aims

- Research INTO practice, such as observing the working processes of others, and

- Research THROUGH practice, where the practice serves a research purpose.

This works as a global description of three different modes but the description is too coarse, general and imprecise to be useful for a discussion about the detailed theoretical and methodological implications these types of research may have (see also Mattelmäki \& Mathews, 2009). An apt summary of these approaches appears in the Practice-Led Research in Art, Design and Architecture, the AHRC Research Review report about practice led research in the UK:

In 1993 Christopher Frayling adapted Herbert Read's model of education through art to describe different ways of thinking about research. He noted that research could be FOR practice, where research aims are subservient to practice aims, THROUGH practice, where the practice serves as research purpose, or INTO practice, such as observing the working process of others. That model has been widely cited by practice-led researchers although, like equally widely quoted work of Donald Schon on reflective practice, it has been easier to use it as a touchstone than to work through its theoretical implications for the individual researcher's project. (Rust et al., 2007: 11). 
This goes as well for the methodological implications. Wolfgang Jonas is one of the voices who are critical of the FOR, THROUGH and INTO typology. Jonas unfolds a quite detailed analysis of these dominating concepts and is critical of their superficiality. He also reveals the inconsistency and un-clarity of these models. He further defines where to find the largest need for development and clarification, stating that:

There can be no doubt that there is progress in research about design as well for design. But this does not essentially contribute to the development of design as a knowledge-building discipline. The challenge lies in the further clarification of RTD' (Research Through Design, author's remark) (Jonas, 2007: 187).

Jonas analyses the three concepts and makes a good attempt to clarify the confusion already inherent in the early suggestions by Frayling. His conclusion boils down to:

\footnotetext{
ABOUT: (replacing into) 'operates from without keeping its object at a distance. The researchers are observers...'

FOR: "The researchers serve designers as "suppliers of knowledge". E.g. market research, user research etc.

THROUGH: 'Designers/researchers are directly involved in establishing connections and shaping their research object'. (Jonas, 2007: 191).
}

This helps to clarify matters a little, but there is a dimension missing: What about research BY design? This mode engages in the research and development from an internal perspective from within the practice. What distinguishes it from research THROUGH design? THROUGH practice probably engulfs BY practice but research THROUGH practice might also include modes where practice serves to generate knowledge for an external agenda. The term Research By Design as I use it emphasises the special inherent nature of design and designing as explorative and generative actions. It is to my mind closer to the unique core of design research.

Even after the attempt by Jonas to clarify the three suggested modes (ABOUT, FOR, THORUGH), they remain unclear and hard to distinguish except the INTO/ABOUT category. None of them actually define research THROUGH or BY design very well. I argue that these iconic models in design research are insufficient. This is because they are too general and global and they can be decomposed into a long range of different modes, distinguished by the relations between practice and research, as I will show later in this paper.

The very core of design research, Research BY Design, produces knowledge by engaging in the generative, in the act of designing. Amongst the few researchers who have been specific and detailed about implementing designing into research is obviously Donald Schön who defined Reflection-in-Action as a technique for learning from practice experience (Schön, 1982). The technique involves both reflections while practicing and after practicing, Reflection-on-Action. Schön has been very influential not only because of the relevance of his writing but also because there has not been produced many alternative and supplementary models equally specific as Reflection in Action. The approach is valuable but has its limitations. Reflection-in-action has been criticised for interrupting and influencing the flow of design actions (Pereira, 2000). This criticism seems less justified if we look at Schön's suggestion as one of few that is particular and specific about practice-led design research. If Schön would be situated in a landscape of additional methods, as one of several possible approaches it would make more sense.

Michael Biggs and Daniela Büchler (2008) make an attempt to clarify the relation between practice and research. They observe that the current conception of this relation is informed by the different national conditions to which they refer (England and Sweden). They 
suggest using criterion from "traditional sciences" to evaluate the benefits of practice-based research in design. They envisage there being three ways in which design practice can contribute to academic research:

- Exploratory practice within a traditional model of academic research

- Practice as a generator of relevant questions that are explored within the structure provided by the traditional model of academic research

- Design practice that claims that it is academic research.

Though they describe a possible role for the designer to contribute in the identification of crucial questions to be researched, to a large degree Biggs and Büchler do not acknowledge practice as a theory building activity. In this model, design practice is reduced to a testing ground and to a device for advancing questions. The use of the term 'hypothesis' in their work indicates that they do not acknowledge the possibility of a bottom-up approach to inquiry, such as grounded theory where the term hypothesis becomes irrelevant. In their view, traditional science is regarded as something unified, and hence models within the 'traditional sciences' that would be more relevant and easy to modify to Research by Design are left out of their approach.

Steven Scrivener (2000) has described the difference between problem-solving projects and creative-production projects and what consequences this difference could have for the modes of research. He describes a possible research design based on reflexivity for creative-production projects. Here he is quite detailed about how reflection is generated from the work 'episodes'. The attempt is useful and valid especially in describing the difference between problem solving and creative work that does not start from problem solving. Also, it describes a way of embedding work into a format of reporting that could be applicable to a doctoral thesis. Still, this formulation has some short comings. It does not describe multiplylayered relations between practice and reflection. In Scrivener's model, reflection seems to be prior to work.

Kristina Niedderer and Yassaman Imani (2008) investigate whether the SECI model from Knowledge Management can be used as a framework for rigorous research in the creative and practice-led disciplines. The SECI model describes four different transitions between tacit and explicit knowledge:

$$
\begin{aligned}
& \text { Socialisation - tacit to tacit } \\
& \text { Externalisation - tacit to explicit } \\
& \text { Combination - explicit to explicit } \\
& \text { Internalisation - explicit to tacit }
\end{aligned}
$$

They state that despite there being a strong focus on practice as a research method, there is a lack of understanding in how to link that knowledge to research methodology. They discuss this relation in the perspective of tacit knowledge (Polanyi, 1967). Practice as such contains both tacit and explicit knowledges and various modes of expression, both verbal visual, and possibly auditive and tactile, that each would relate differently to reflection. This multimodal and medial view on practice as knowledge production is especially valuable and important. It establishes an approach to practice that maintains its richness and multi-layered potential (see also Morrison et al. 2010 in press).

Halina Dunin-Woyseth has drawn up a model of how the relation between architectural practice, knowledge production within architecture and established academic fields have developed over the past 40 years within the doctoral scholarship in architecture in the Nordic countries (Dunin-Woyseth, 2009). The model shows that this is a dynamic 
development and that the dialogue between scientific research and creative practice is increasing, while creative practice itself is developing towards transdisciplinarity and emerging as a confident research area. It also demonstrates development towards an increasing multiplicity. Related to this complexity, Thomas Binder and Johan Redström (2006) argue that design research may be conducted in different modes and contexts indicating that these options and this complex landscape eventually needs to be drawn.

The latter descriptions here share a view that is inclusive and where the richness of design practice is engaged and allowed to play a full role in design research. This point towards more complex and lateral research designs. This is a very important development also earlier addressed by the author (Sevaldson, 2000, 2008a). The richness of design as a field being interdisciplinary and spanning across different domains of culture, economics technology etc. indicates that multiple research approaches are possible and that both the design process and research by design should reflect this richness.

Other design researchers who have contributed to the field are, for example, Nelson and Stolterman (2003) writing about design in an unpredictable world, Scrivener (2004) contributes to the understanding of the uniqueness of research in art and design, Swann relates doing and making with research with references to the framework of action research and translates this framework into design practice (Swann, 1999). Also worth mentioning is the Swedish anthology on design research Under Ytan (Harvard et al., 2007) that provides a wide and inclusive review of the field of design research.

\section{The problem between design research \& the 'traditional sciences'}

The examples above demonstrate a lively discussion in a field that is emerging. But some of these examples also reveal a contradiction between design practice as knowledge generating activity and what is called 'traditional sciences'. On one side we find a lack of understanding amongst 'traditionalists' of what is particular about Research by Design as knowledge production. This position prevents other sciences from learning from design. On the other side we find a lack of understanding as to what other sciences could contribute to design research. This prevents design research from learning from other sciences.

To understand what design research is and might be, we need to map the manifold and rich landscapes of design research. We also need to add new and develop further the concepts for being in that multiply complex and interactive, genre and field-crossing activity that constitutes the very nature of Research by Design. It is crucial to understand the nucleus and field of gravity in Research by Design where critical and reflective insider perspectives that are derived from first person knowledge from practices are central.

One problem in these contradictions is caused by a simplistic interpretation of 'traditional sciences' as something uniform that follows only very limited and prescribed modes of enquiry. This is a view on other sciences that is still quite prevalent amongst design writers (Marshall \& Newton, 2000). The problem with this claim is that it is imprecise. There are actual foundations for design research that are comparable to those in the sciences. We need to be specific about what sciences we talk about and what parts of design research we are comparing them with. For example, there are established research practices within practice-based research in such fields as nursing and there are theories that relate to, for example, constructivist learning practices. Again, reflexive moves, between where and how knowledge is made shifts between theory and practice, are important for design research.

Binder and Redström (2006) proposed a view for design research in which they relate design research with other relevant research fields. They acknowledge the complexity of design research and that several different modes of knowledge production and theories can live together. Relevant theories from the social sciences which have frequently been used in design research are Activity Theory and Actor Network Theory. We also can find design 
research that relates and draws from research within engineering, biomimetics, ecology, management etc. Design research may span across many established fields of inquiry, from hard to soft, and in each of them have its own genuine take. I have earlier argued for such a view on design research (Sevaldson, 2000).

Another discussion creates a division between design research as fuzzy and undefined while other sciences are regarded as being rigid and not engaging in fuzzy problems. If we look at social sciences like ethnography this divide seems superficial. Here we find methods of investigation that involve living within the system one investigates. Through lived practice one accesses the deeper layers of interpretation that would be inaccessible to distant observation. In this way, these research practices engage in very fuzzy fields of investigation in an inductive, bottom-up, theory building process. This aspect of 'traditional sciences' is often not understood in design research. Perhaps this is a question of not all design researchers having received formal research training from within an established discipline, such as anthropology.

It is reasonable to believe that design research is heavily influenced by formal academic researchers coming from the outside of design and dominantly from the humanities and engineering sciences. Halina Dunin-Woyseth (2001) describes the position of history and criticism within architecture, documenting how several writers emphasise the importance of history and criticism. Criticism is not defined but is implicitly understood as the ongoing general discourse found in the field of architecture. In the Anglo-Saxon context we find a triadic concept of History, Theory and Criticism. In design domains, these concepts were assimilated early (Margolin, 1989) and they have in the mix of the digital and physical been reconsidered with reference to emerging practices and challenges to theory as part of theory building.

Today, we regard design as a multiple activity spanning the whole spectrum from the hard edge to the soft. Ken Friedman (2003) describes six knowledge domains in the design field: natural sciences, humanities and liberal arts, social and behavioural sciences, human professions and services, creative and allied arts, technology and engineering. A problem appears when this wide span of fields is dominated by one of them, the humanities. Such a background is not well-suited to especially lead research in the making disciplines where looking into the future, and the challenges of emergent developments, are central and where simultaneously engaging with social life, contemporary cultural trends, emerging technologies, sustainability and politics is important and where innovation as such is central. It is therefore no surprise that when we talk to hard-nosed natural scientists, engineering researchers and systems thinkers from management and newer fields within the humanities like media studies, the dialogue is easier for many research-by-design researchers. In these fields we will find ways of researching that are much closer to the making disciplines like design. Similar observations are apparent in the report on artistic research to the Swedish Research Council (Dunin-Woyseth, Karlsson, Langkilde, \& Paavolainen, 2007).

To be just, we need to state that the humanities are also not a unified entity and that there are many valuable contributions from that side. Especially when humanities meet new media there seems to be a productive change in the approach as shown by e.g. Johanna Drucker (2009). Some design historians have been able to contribute with valuable knowledge to design research as for example Jan Michl's (2002) reflections on design as re-design. While others have actually moved towards the making and doing participating in research by design such as Andrew Morrison (2010 in press).

Nevertheless it is reasonable to believe that the influence of the traditional humanities and engineering sciences in design research has contributed to the current dichotomy between what is regarded design research and 'traditional science'. I sense a natural defensive reaction by many design researchers with a background from the core disciplines, because they feel 
their territory is threatened. Designers and Architects teaching at academic institutions refuse to have others defining their discipline. As a result, they tend to over-emphasise the differences between design research and other sciences at the cost of their similarities, and they tend to look at the sciences themselves as uniform. While this reaction is understandable, it is unjustified when it interprets 'traditional science' as something unified and something totally in contradiction to design research. In the so-called 'traditional sciences', we find a variety of approaches: one such approach is Grounded Theory (Glaser \& Strauss, 1967) that builds theory from the bottom-up so that the concept of the hypothesis becomes inappropriate.

Visualisation has become central in the hard sciences, in different fields such as astronomy, medicine, fluid dynamics, mathematics, quantum physics, but also in the soft sciences where e.g. complex social systems need to be understood (Miller \& Page, 2007). The relation between visualisation and text is ostensive where the text reflects upon what the image means. Methods for involved research have been developed in participation observation, rendering the 'traditional' scientific concept of distance irrelevant (Jorgensen, 1989). Research on and into practices has reached a mature state with the development of methods and theories especially in medical practice (Robson, 1993). In relation to all of this, creative practices are not unique for the designer or artist, but are found across all sciences and also in other fields. (Csikszentmihalyi, 1996). Understanding visual thinking as a central part of 'normal' thinking has long been proposed (Arnheim, 1969).

Another development that pertains to understanding the fuzziness of designing and researching by design derives from understanding designing as beyond sheer problem solving. Problems in social systems including design are described as 'Wicked Problems' compared to those, for example, in the natural sciences as 'Tame Problems' (Buchanan, 1992; Nelson \& Stolterman, 2003; Rittel \& Webber, 1973). Wicked problems are typically ill-defined and you know their formulation only when you have found the solution. This implies an iterative explorative and generative way of getting to know the problem. Knowledge is built through designing. The description of wicked problems contributes to this increased understanding of the nature of design.

There are several other 'soft' perspectives coming from 'traditional' sciences that have been influential in design thinking. Amongst them we find for example the concept of Reflexivity(Alvesson \& Sköldberg, 2000) and relations and translations in Actor Network Theory (Latour, 2005). For the sake of the frame of this paper we will only point to these here by mentioning their importance in helping establish a less rigid understanding of scientific reasoning in design. Another valuable source is Ronald N. Giere (1991) who shows the central position of common sense and judgment in all scientific enquiry.

All the modes of knowledge described in 'traditional' sciences tell us that:

- Design research as knowledge production is not principally different from other modes of knowledge production.

- Other sciences also work with visual material partly comparable with visual material in design.

- Inductive and explorative methods and theories are accepted in many sciences.

- The distance between researcher and subject is negotiated in other sciences.

- All research has a component of craft or practice. This might help bridge the gap.

- Other sciences also have a generative aspect or an aspect of innovation.

- Other sciences also deal with wicked problems but they are more at stake in design than in many other fields.

- There is an important difference in the degrees and importance of the visual and creative. 
- There is an important difference in the very wide scope of design research.

- There is an important difference in the design professions and practice lying at the nucleus of design research.

- There is a uniqueness to design when we regard it as a mode of knowledge production, where explorations, discoveries, innovations, and the generative are inherent features of designing.

When we have accepted this complex picture of the 'traditional' sciences and its relation to designing we can understand design research as equally manifold and complex. Fortunately, we have an increasing number of project-based examples suggesting that there are many different possible ways of knowledge generation in the field of design. Examples are found, as in the new Design Research Institute at RMIT (2009) in Melbourne. Here they develop a transdisciplinary approach to design research, creating settings where different types of designers are able to learn from each other. We also could mention some recent doctoral theses that push the borders, themes, and formats of research, and that connect well to design both as a practice and as a mode of reflection. Examples are Otto von Busch's doctoral thesis FASHION-able (Busch, 2008) and Ramia Mazé's doctoral thesis Occupying Time (Mazé, 2007). Ranulph Glanville puts it this way:

We who are interested in design and in researching into it are still inclined to insist we should prosecute our research according to the old no longer sustainable view of (scientific) research: which view removes from design - and from how we consider and present it - which makes it central, important, and valuable; exactly that which characterizes it. Even while scientists come to realize their creative involvement in their processes (Glanville, 1999 : 89-90).

To understand design research more fully it might be useful to draw a rich landscape of possibilities that allows for any variation and innovation in approach, method and practice. In short, we need to become more particular and yet also more specific.

\section{Cross-section 3: Global perspectives in design research}

In this section I will cut yet another cross section through design research to go into some of the world views to be found in design research. The aim is to show that there indeed are many different possible positions in design research and that these positions might well live together. This might make design research appear as a confusing field but it is also a sign of ongoing processes in the formation of design research as an academic domain. Design research is in the midst of a historical process of defining itself as an established field of knowledge production. This is a process that many other sciences have previously gone through (Dunin-Woyseth, 2001).

\section{The making disciplines \& Mode 2}

In their book The New Production of Knowledge Gibbons et al. (1994) define a new mode of knowledge production they call Mode 2. This concept has been frequently referred to by design writers like Halina Dunin-Woyseth (2005) who situates design research in Mode 2.. Mode 2 is described in the following way by Nowotny (2004):

- Research is carried out in context and in a mode of applied research. Research questions are formulated within the applied research in communication between stakeholders.

- Multiple actors bring differentiated skills and knowledge.

- Transdisciplinarity is the normal state of the research projects. 
Mode 2 of knowledge production is a non-fragmented inclusive approach to research. It is hence able to address the interlinked problems of the modern world. Not only does Mode 2 seems to fit some of the designers' ways of researching but it seems to become more important when we look at the increasing complexity of the challenges that face the designer.

\section{Epistemology, praxiology \& phenomenology of design}

Nigel Cross suggests that we can divide knowledge production in design into three main perspectives:

- Design epistemology - study of designerly ways of knowing

- Design praxiology - study of practices and processes in design

- Design phenomenology - study of the form and configuration of artefacts (Cross, 1999).

I suggest that the separation of epistemology and praxiology in this model is unfortunate. This separation reflects an ancient division between practice and theory that is about to be bridged in design research where reflection and practice are about to be tied together in more intimate ways. I would argue that exactly in design research this divide is creating difficulties. The concept of designerly ways of knowing seems totally tied to design practice. This is also stated by Jonas (2007: 187): "So since there is no substantial progress in defining design research, I will follow the concept of about/for/through, which- by means of 'through' offers the semantic category of a designerly mode of knowledge production". Therefore we will here be less interested in the epistemology separated from practice.

One of Cross' motivations to coin the term "designerly way of knowing" was to argue against domination from the "traditional sciences" and the field of art research. Cross advocates "designerly way of knowing" as different than "imitation of science" or "... design as a mysterious, ineffable art". The motivation is "... avoiding to swamping our research totally with different cultures imported either form science or art" (Cross, 1999: 5).

As discussed earlier, the relation between design research and other adjacent fields of knowledge production should now be close to reaching a matured state where, on the one hand, we are able to connect, communicate and learn from others, while on the other hand we are developing confidence in our core competences. While the genuine voices in design research are increasing in numbers and volume, the swamping effect Cross mentions becomes less of a problem and we are able to relax the relation to other fields, reaching positions that make more fruitful exchange possible.

\section{The Lab, the Field, the Gallery}

Ilpo Koskinen, Thomas Binder and Johan Redstöm (2008) suggest three arenas for design research: the Lab, the Field and the Gallery. These arenas address mainly Research by Design where there is an inseparable connection between research activities and design ones:

- The Lab resembles the experiment in natural or technical sciences but even more experimental psychology. They seem to propagate a view on the lab as quite rigid and as a transparent process.

- The Field concept builds on interpretive social science, participatory design, action research and similar approaches. The context of the Research by Design is real life.

- The Gallery is a format for the dissemination of the artistically oriented design research. The gallery exhibition plays the role of the publication and the object is central. 
This model can be criticised for mixing modes of research with modes of dissemination. While the lab and the field can said to be research modes with implications to certain research designs and how the research is done, the gallery is regarded as a medium for publication. If we redefine the gallery as a device for the Design Experiment instead of emphasising its dissemination characteristics it makes sense. The Gallery indeed can be a very powerful device for financing and conducting spatial experiments as basic research as shown in the BARELY series (Barrett \& Sevaldson, 2007, 2008).

\section{The Rich Design Space \& the Rich Design Research Space}

I have earlier suggested looking especially at the makeup of design spaces for projects that address very complex problems (Sevaldson, 2008a). The design space is understood as the physical, digital and social space created around the project. Other writers have had similar or related ideas on the concept of richness (Tevinio, et al., 1990) and the design space (Lynn, 1999; Leerberg, 2004).

The Rich Design Space becomes especially important when looking into modes of Research by Design where the design process becomes the central device for research. This has led one step further to the suggestion of the Rich Design Research Space (Sevaldson 2008a). This space includes everything from the former concept but integrates additional research methods, an additional analytical and reflexive level and produces research dissemination in an academic peer reviewed format. This research level of the complex process lives in a lateral relation to the practice, and they feed into each other. The Rich Design Research Space is a concept for Research by Design, where very complex design tasks are addressed and researched in holistic, interdisciplinary, systems oriented ways. It is well suited to address the important contemporary challenges of globalisation and sustainability.

\section{The Design Experiment \& Basic Research in Design}

Mattelmäki and Mathews (2009) claim that there is no such thing as basic research in practice-based design research. They describe the situation as given: design research is measured according to its relevance to practice. This seems to be a logical conclusion since practice is an inherent element of the research. But if we start to distinguish and analyse the different modes of Research by Design the picture opens up. What commonly is called experimental design does not necessarily have the intention to feed into commercial practices. The notion of the experiment in design is quite different from the traditional scientific experiment. While the scientific experiment is about isolating a limited and fractioned part of the world to create a repeatable output as validation, the design experiment is about provoking change and iterative imaginative steps forward. The design experiment often has an element of 'not always knowing what you are doing', a wicked problem approach and postrationalisation. But both can be seen as closely related to basic research. Basic research is concerned with the fundamental issues in a knowledge field. These issues are internal in the sense that basic research addresses the field itself and not outsider audiences or application in the real world. It is very often hard to see the final outcome of basic research but it typically has enormous influence on commercial applications later.

Experimental design practice, when conducted as part of research, has a similar function as basic research in other fields. Experimental design is mostly found in the academic institutions, as research conducted by academic staff, master studios or $\mathrm{PhD}$ projects. It is typically seen in the gallery. Only after longer periods of investigations will this type of research eventually reach a stage where applicable results are found. This is research that is not possible to fund within the normal applied research funds where company 
participation is needed. Therefore, it needs to be funded by the academic institutions themselves.

Experimental design as basic research is design centric. This means it is about changing practice from an internal designer perspective, and not about improving interaction with external partners (users, clients, companies). In my own work, the conceptualisation of digital design techniques in my $\mathrm{PhD}$ thesis, and, later, the development of a concept for System Oriented Design, are examples. The latter was a result of several years of quite internal experimental design processes under the label 'Designing Time' (Sevaldson, 2001, 2004a) towards a state of implementation into design for businesses (Sevaldson, 2009). This project moved from a state of basic Research by Design to applied Research by Design.

\section{Basic, Applied \& Clinical research}

Ken Friedman (1999: 508-521) describes a model of Basic, Applied and Clinical research: "Basic research involves in the search for general principles.... Applied research adapts the findings of basic research to classes of problems... Clinical research applies the findings of basic research and applied research to specific situations".

Despite that the term clinical is somewhat difficult and easy to misinterpret, this distinction is helpful when relating different modes of research to practice. Another issue is that this model, as it is described, takes for given a flow of knowledge from basic research via applied towards clinical research. This is of course not the complete picture. On the contrary, most of the important questions in design and design research arise from practice or experimental design and there is a feedback cycle from practice and applied research into basic research.

I am convinced that the question about basic research in design research is very important to warrant it being discussed further. A proper investigation and development of the notion of basic research in Research by Design will show that there are indeed many projects and developments that fall into this category. This is an important realisation because of the financing of these projects. Academic institutions need to be responsible for this research to thrive.

There are other world views and models not discussed here. One example is the $\mathrm{C}-\mathrm{K}$ theory that attempts to put knowledge and concepts into a logical relation. (Hatchuel \& Weil, 2003). The further mapping of the field is obviously necessary.

\section{Possible relations between practicing \& theorising}

In the AHRC report the authors formulate the main topic of this subsection:

Practice is an activity which can be employed in research, the method or methodology must always include an explicit understanding of how the practice contributes to the inquiry and research is distinguished from other forms of practice by that explicit understanding (Rust et al., 2007: 11).

This suggests a one way relation between the inquiry and practice. Practice is regarded as serving the inquiry. I will try to do what the AHRC report suggests by describing more explicitly possible relations between practice and reflection but regarding these relations to be more complex than suggested here. How can practice and reflection relate to one another? How can practice and reflection feed into each other? To do this, we first need to look at some major perspectives relevant to what kind of relations we can define.

\section{First, second \& third person perspectives}

The notion about the first, second and third person perspectives used here is borrowed from Action Research (Stringer, 1996). The first person perspective corresponds with the practising 
individual designer, the insider perspective were the designer has access to tacit knowledge and deep process knowledge. The second person perspective corresponds with group work, and the third person perspective corresponds with the traditional observer position.

\section{Looking at design as an activity: $1^{\text {st }}$ person perspective}

Looking at design as an activity changes the perspective to be closer to the making (the first person perspective). One observes from within the activity by taking the role of participant observer or being immersed in the making process as the designing individual. Concepts like reflection in action are found here. However, in a Research by Design view, more is at stake than simply immersion in design. Designer-researchers work reflectively, moving between creative action and critical reflection. Reflection and creation is layered and feeds into each other and is closely bound together in a symbiosis that goes beyond the remote position of the observer. Within this perspective, one is able to understand the potential and implications inherent in the design activity and is able to generalise and communicate. To my mind, this is an important and under developed field of knowledge production in design research. The advantages and disadvantages of an insider-practitioner perspective have been discussed by Robson (1993) The disadvantages are summarised as lack of time, research expertise, research confidence, preconceptions and others. The advantages are insider knowledge, less implementation problems, and practitioner-researcher synergies.

\section{Research in action: $2^{\text {nd }}$ person perspective}

Collaborative design, participation and group work are all features of action research. This second person position allows multiple perspectives and is geared towards the community and interaction. This perspective is important and it is rapidly growing, and co-design and strategies of involvement are becoming more defined.

\section{Observing design as a phenomenon: $3^{\text {rd }}$ person perspective}

Observing design as a phenomenon involves an outsider perspective (third person perspective) through which one tries to understand design by observing it. The intention of this position is to find some patterns in the phenomenon that make it possible to generalize knowledge. The very requirement for this position is that there is a certain stability in the phenomenon observed. If it is under too rapid change or it varies too much between individuals in the field, generalizing is very difficult. The most established way of looking at design from a third person perspective is as design history. Other examples are researching design from economical perspectives, as strategic marketing advantage, as contemporary cultural expression, and from a production technology point of view. Though the third person perspective is a valuable perspective, I argue that it is less important and central than the other two perspectives. It falls outside the core of design research because it does not involve practice and it does not necessarily depend on the designer researcher but can be conducted by outsiders like specialists in history, economy or marketing though designers can contribute with valuable insights. Still designers might provide a special insight when taking a third person position as shown by Trygve Ask (2004) In this doctoral thesis Ask looks at Norwegian design history with the background of a design practitioner.

\section{Regarding design processes as stable or dynamic}

A central problem in design research is the nature of the phenomena we study. Are the design processes stable or are they dynamic and under constant change? Two questions about the phenomenon of design practice arise: 1) The stable perspective: how are we designing? 2) The dynamic perspective: how can we design differently? 
The stable perspective starts from the assumption that designing is a phenomenon that is relatively stable, not unlike any natural phenomenon. It is only superficially disturbed by external influences, such as new technologies and changing social conditions, but it is very nature stays the same. The design process is closely related to creativity which is also regarded as a stable though enigmatic phenomenon, but it is possible to understand at least parts of it through observation and analyses. The ultimate output of this view results in prescriptions for the process and for design methodology. Almost all existing writings addressing design processes are based on a stable view. The aim is to generalize knowledge of the design process. This includes writers like Brian Lawson and Nigel Cross. (Cross 2007a; Lawson, 1997). Lawson describes how designers think and Cross suggests the concept of 'designerly way of knowing' as something particular and, hence, at least partly stable. The methods to research these phenomena are often the use of interviews and protocol analyses as described by Cross (2007a). This perspective results in descriptive research (the exploration of what is there).

A dynamic perspective is radically different from this. It indicates that there is no given object of investigation when looking at the design process and ultimately it looks at the design process as a designed artefact. The research engages in the re-creation of that artefact. The question is not what is there, but what it potentially might be. The dynamic perspective recreates design as a means of understanding problems within design but also far beyond its borders. This type of research is normative and generative.

A paper that is relevant in the discussion about stability and observer positions as well as observer/actor relations is Ranulph Glanville's 'A Ship without a Rudder' (Glanville, 1994 : 6). The paper discusses stability of systems and the insider and outsider position in the context of first and second order cybernetics. The observer in an inside position is part of the systems observed and stability is defined by the observer.

Kees Dorst (2008: 5) criticises process models in design that ignore the "context the object and the actor". He also takes up 'anomalies' in design methodology. Many experienced designers claim they do not use methods. It is not satisfactory to dismiss this claim by arguing that they in fact use methods but that these are implicit. Dorst also describes the situation where practitioners seem not to pick up on the methods developed by design research. Dorst's observations are relevant to our approach here where we state that there is no such thing as a generalizable design process. It would probably not be something we would want to strive for. Hence I support the dynamic perspective. As Dorst suggest, this involves looking at the design process as involving the context and the actor. Each project asks for a slightly unique process. Each individual designer practices in a slightly individual way. The mapping attempt presented below is not about reaching a limited number of methods but to unfold possible relations between practice and knowledge production. All these observations lead to a view of the design processes being a dynamic phenomenon, varying according to individual and case. Though we can observe individuals repeating patterns in their processes, the phenomenon at hand is highly fluid and emergent.

This view is reinforced by creativity research (Csikszentmihalyi, 1999; Gruber, 1988; Sternberg \& Lubart, 1999) where creativity is understood as a complex phenomenon composed of different individual, cultural, and social conditions and practices. Csikszentmihalyi calls this a systems approach to creativity. We can look at design practice in a similar way via a systems approach to understanding design practice. Since all the involved conditions are dynamic and change in the short term but also historically, creative practice is hence changeable. The process can be altered by altering its structure. This can be done by inductive, explorative, and experimental design practices. The design process is a systemic artefact that can be designed. Looking at the design process as a designed artefact results in generative research with the aim of developing, and describing possible design processes. 
More importantly, it results in research about the structures and conditions that make up and influence the creative practice. The author has argued for this view previously (Sevaldson, 2005, 2008a).

Further, we can argue that research is also an artefact. I will not go into a big discussion about relativism but apply a pragmatic position towards the production of knowledge. There is no doubt that the construction and design of research is something to be aware of. Also commonly used outside the realm of design is the term research design. Booth, Colomb and Williams (2008) look at research as a craft. This perspective might be useful to keep in mind when attempting to bridge the gap between theorizing and practising and when looking at research as a skill and practice. I have earlier addressed this topic and a discussion what research design might be in design research (Sevaldson, 1999). Ranulph Glanville states:

Design is the key to research. Research has to be designed. Considering design carefully (making theory from or even researching it) can reveal how better to act, do research - to design research. And how better to acknowledge design in research: as a way of understanding, acting, looking, and searching. But design should be studied on design's terms. For, design is the form, the basis. And research is a design act (Glanville, 1999 : 90).

\section{Being specific in exploring relations between research \& design practice}

To further unfold the possibilities and close into a discussion that potentially can become useful for helping new design researchers to become conscious about their positions and research designs we need to become more specific and produce examples. My attempt to become specific is organised in two steps: Step one: Defining variables that help distinguishing different relations between practice and reflection. Step to that produces a series of examples or prototypical research designs.

\section{Nine variables for design research}

In the next step of unfolding the complexity of the possible relations between the creative design practice and research I found it useful to create an analytical tool made out of a number of variables that might describe the relation between practice and reflection. During this process I ended up with nine variables. The variables are a collection of concepts discussed earlier in this paper, like the $1^{\text {st }}$-person, $2^{\text {nd }}$-person, $3^{\text {rd }}$-person perspectives, and other more implicit issues like the axes between process oriented approaches and result oriented approaches.

\section{Descriptive research - Normative research - Generative research}

This works as a singular scale where one can imagine interpolations between the three modes with normative in the middle.

2. Basic research - Applied research - Clinical research

As described by Ken Friedman but with a slight reinterpretation of clinical research being a more active mode of knowledge production and also feeding back into the others states, as discussed earlier.

3. Library - Lab - Field - Gallery

I added the library to Binders and Redstöm's earlier discussed concept of the Lab, the field and the gallery as it seems to work well. One can imagine interpolations between the four states.

4. Process oriented - Result oriented

As stated.

5. Stable - Dynamic view on the design process

Discussed and explained above.

6. $\mathbf{1}^{\text {st }}$-person, $2^{\text {nd }}$-person, $3^{\text {rd }}$-person

Discussed and explained above 


\section{Top-down theory building - Bottom up theory building}

Refers to deductive, inductive, and abductive modes, testing a pre-formulated hypothesis or building theory from the ground (grounded theory). Discussed earlier.

8. Retrospective study - Contemporary study - Forecasting

Retrospective can be historical studies but also post rationalisation about an individual praxis, contemporary refers to reflection in action but also to case studies as defined by Yin (Yin, 1994), forecasting involves future speculations, generative work and innovation.

\section{Isolated - Contextualised}

Isolated refers to a fragmented approach where certain things are looked upon separated from the context similar to one would do in a traditional scientific experiment. Contextualised indicates a systems oriented approach looking at the issues in the field or in real life settings.

\section{Prototypical design processes}

The next step was to create prototypical design research processes using the nine variables as a tool to distinguish them. The seven examples of such prototypical design research processes shown below are sorted so that we move from an outsider perspective towards a more embedded insider perspective and from stable perspectives towards more dynamic ones. Obviously by systematically combining the variables more prototypical design research processes would be possible. The point here is only to demonstrate that by being specific about the relations between practice and reflection one can create numerous research designs for any thinkable situation in research by design.

\section{Research into practice}

Definition:

Looking at other peoples practice, observing practice and understanding it from an outsider perspective like an historian or ethnographer.

Variables:

1) Descriptive. 2) Basic 3) Library/field. 4) Process and result oriented. 5) Stable. 6) $3^{\text {rd }}$ person perspective. 7) Top-down theory building. 8) Retrospective. 9) Contextualised/isolated.

Description:

Research INTO practice. Basic research. Regarding practice as a fairly stable phenomenon that can be observed and understood similar to natural phenomenon. Attempts to increase the understanding of the phenomenon of design both as a process but more often as product. Design history.

Relation between the practice and research:

Distant relation. Observer-object relation. Mostly retrospective.

Advantages:

Neutrality and distance. Less problems regarding bias. Generic knowledge that could be verified in large scale studies.

Disadvantages:

Problems of relevance. Neutrality and distance does not give access to the most central aspects. Easy to bias study because of chosen worldview. Based on a stable view of the creative practice. Not ideal for understanding design as an artefact under construction. 


\section{Retrospective practitioner study}

Definition:

Looking back at your own practice and analysing it retrospectively.

Variables:

1) Descriptive. 2) Basic 3) Field/Gallery. 4) Process-oriented. 5) Stable/dynamic. 6)

$1^{\text {st }}$ person perspective. 7) Bottom up theory building. Abductive. 8) Retrospective. 9)

Isolated/(contextualised).

Description:

Retrospective-analytic. Post-rationalisation. Applied and basic research. The practice itself is regarded as fairly stable while one through intimate insider knowledge or from various outsider perspectives tries to uncover how things were done methodologically. Transforming one's own work from being tacit to becoming explicit.

Relation between the practice and research:

Close relation between practice and research through $1^{\text {st }}$ person perspective.

Advantage:

Time creates a valuable distance to revisit and re-understand your own practice. Overcomes some of the $1^{\text {st }}$ person disadvantage of lack of distance.

Disadvantage:

Certain phenomena are lost because of loss of memory. Longer feedback cycle because there is a disrupted or slower feedback from research to practice..

\section{Contemporary practitioner study}

Definition:

Looking at and analysing ones own practice simultaneously while practicing.

Variables:

1) Descriptive. 2) Applied/Clinical. 3) Lab/Field/Gallery. 4) Process-oriented. 5) Stable. 6) $1^{\text {st }}$ person $/ 2^{\text {nd }}$ person perspective. 7) Bottom-up theory building. Abductive.

8) Contemporary. 9) Isolated.

Description:

Applied research is generalised to contribute to basic research. Observation and reflection leading to systematising and generalising. Reflexive. Can be reflection in action, case study driven and participant observation.

Relation between the practice and research:

The practice itself is regarded as fairly stable while that through intimate insider knowledge or from various outsider perspectives tries to uncover how things are done methodologically or how things operate in a cultural context.

Advantages:

Reflection in action allows direct feedback loop to practice. Lack of distance draws on insider knowledge

Disadvantages:

Reflection in action can disturb the flow of the process and puts additional work loads to the process. Lack of distance might bias results.

\section{Practice research in action}

\section{Definition:}

Design and community practice in a real life context is analysed and changed in real time.

Variables: 
1) Generative. 2) Clinical. 3) Field. 4) Result/process oriented. 5) Dynamic. 6) $1^{\text {st }}$ person and $2^{\text {nd }}$ person perspective. 7) Bottom-up theory building. Abductive. 8) Contemporary. 9) Contextualised.

Description:

Interactive, participative, collaborative research. Clinical (applied) research. Changing design and community practices through actions.

- Action research

- Practice as research (Research by Design)

- Practice through research (application of research into practice)

Relation between the practice and research:

Knowledge is generated in the action. Real world aspects are investigated, created and reflected upon in real life context through interventions.

Advantages :

Real life context and interventions create immediate response and instant knowledge. Multiple stakeholders and participants are great sources of information and knowledge. Multiple actors might help buffer preconceptions.

Disadvantages:

Fuzzy, dynamic and complex action field poses challenges to the generalisation of knowledge. Large amount of information challenges resources and co-ordination.

\section{Science \& Technology Studies (STS)-driven research by design}

\section{Definition:}

New design practices are developed as a response to new technologies and knowledge. Variables:

1) Normative. 2) Applied. 3) Lab/field/gallery. 4) Result and process oriented. 5) Dynamic. 6) $1^{\text {st }}$ and $2^{\text {nd }}$ person perspectives. 7) Bottom-up theory building. 8) Contemporary/forecasting. 9) Isolated/contextualised

Description:

Applied research, might lift out some basic research. Application of research/new technologies etc into practice. The resulting effect is development of new practices. Technology pull. For example research would unfold a new area for design practice or a new relation between design and client. Or new practice is developed from new technology that creates an opportunity for a new 'design material' e.g. RFID.

Relation between the practice and research:

Practice is redefined and reinvented based on the needs or push of new technologies or knowledges implemented into the area of design. Very strong impact from the research into the practice. Might start with tentative explorations and concepts that are tested and over time modified to serve a commercial practice.

Advantages:

Systematising this perspective might create a larger awareness towards implementation of new technologies and knowledges into design. Big advantage in doing this more actively than just by assimilation over time. Large innovation potential.

Disadvantages:

This approach might become narrow in its scope. Technology push is some times dominating on the costs of theorising. Results are often shown through innovations rather than generalised knowledge. 


\section{Experimental design practice \\ Definition:}

The practice is experimentally changed and modified to explore and develop specified investigations, research questions or effects ('experimental practice').

Variables:

1) Generative. 2) Basic. 3) Gallery. 4) Result and process oriented. 5) Dynamic. 6) 1and 2nd person perspective. 7) Bottom-up theory building. Abductive. 8) Forecasting. 9) Isolated.

Description:

Practice is actively changed to 'see what happens'. What-if mode of thinking. Based on a close relation between process and result. By changing the process the result will implicitly change. Gallery is often meant in its literal sense since the art genre provides a great opportunity for this mode of design. Innovation-oriented approach. Results are often implemented into normal design practices by others.

Relation between the practice and research:

The experimental practice is regarded as the framework for the research method. This approach is result-oriented in its main perspective but is process-oriented in its method. There are strong feedback loops between the practice and the writing/generalization. Material and text depend on each other/are equally important. Theory is built from the phenomena explored and developed. Heuristic-explorative. Based on intimate knowledge, $1^{\text {st }}$ person perspective and creative exploration, systematization of concepts and communication.

Advantages:

There is an intimate relation between practice and research. Practice is altered as a result of active developing the research design. There is a great potential in this approach for making progress within design research.

Disadvantages

There can be distance from the experimental practice towards implementation into mainstream practice. This phase needs further development.

\section{The inductive \& iterative theory-driven $\&$ theory-driving experimental design} research practice

Definition:

New design principles, solutions and knowledge are developed through design experimentation and writing, informed by and contribution to existing and new theories and practices.

Variables:

1) Generative/normative, 2) Basic and clinical. 3) Library- Gallery. 4) Result/processoriented 5) Dynamic. 6) $1^{\text {st }}$ person, $2^{\text {nd }}$ person, $3^{\text {rd }}$ person perspectives. 7) Top-down and bottom-up theory building. 8) Retrospective/Contemporary/Forecasting. 9) Contextualised/isolated.

Description:

Complex and multi-layered design concepts are developed within a theoretical framework and an experimental setting (Art gallery, Experimental lab etc). There is a close connection between avant-garde discourse and new practice driven by technology and contemporary cultural influences. There is easy alternation between top-down theories, design experiment and bottom-up theory building. Theory heavy. Found in architecture in periods. 
Relation between the practice and research:

A predefined concept that is multi-dimensional and needs a wide and deep investigation into materialisation is tentatively developed towards its materialisation. The experimental practice feeds back into the concept. The concept can only be developed and imagined through the practical response.

Advantages:

Design knowledge of e.g. effects achieved by multi-layering of knowledges, media and means are tried out and their efficient application developed. This is knowledge that can not be developed in any other way.

Disadvantages:

Basic research that needs implementation strategies. The theoretical overbuild tends to become fuzzy and inaccessible. It is some times hard to distinguish the theory as factual information from theory as poetic inspiration.

\section{Composite research designs}

The above prototypical design research processes are idealised descriptions. In a real research project different modes might live together. The critical application of two or more perspectives and approaches in design research I call composite research designs. When talking of rich design research then a composite take on the methods is plausible. Reading, observing, practicing and thinking are natural modes that would appear together. When discussing the idea of composite design processes as a means to address very complex research topics, this approach is based on an idea of a process - problem parallelism: complex problems are best addressed with complex processes. Though the idea of product process parallelism rightfully has been challenged by Gedenryd (1998), it still seems to maintain its value. Gedenryd's critique helps us prevent taking this relation for granted, but ask that we reconstruct it in every instant according to the present needs. My continuous belief that the idea of product- process parallelism at least contains some value is based on experience in researching and developing systems thinking in design as a means of addressing very complex issues, and the concept of richness in both design processes and research by design (Sevaldson, 2008b).

The categories presented above are not meant to suggest complete research methods, but they can be modes of operation that might be combined and appear together with other modes of research, be it literature studies, historical studies or technological studies. To meet the challenges of complexity in design research we need inclusive research approaches. Some such inclusive design research models have already been suggested. The conception of the Case Study as conceived by Robert Yin (1994) is an important example of such inclusive research designs. It allows interpolating and triangulating between several different modes of investigations.

Another view suggested by the author, is the concept of an Integrated Conglomerate Approach to design research (Sevaldson, 2000). This concept acknowledges that many kinds of investigations can be adequate within design research and that hence several perspectives and approaches as well as theories and methods might co-exist. This approach is developed further in Hybrid Processes were I argued that the design process has become multi-medial and that strategizing this would generate advantages for design processes that address very complex issues (Sevaldson, 2004b, 2005). This view was developed further in the Rich Research Space where this multi medial concept was contextualised to include the physical and social space for design (Sevaldson, 2008a).

Another perspective that needs to be explored further is the second person perspective. It involves group-work and collaboration and, hence, inherently different views between stakeholders. Collaboration in design has been researched by for example the co-design group 
at the Danish Design School (Binder \& Brandt, 2008) and by Jan Capjon (2004). Investigating the collaborative aspect of design research in relation to the categorising done here would probably expand the horizon.

In summary, a systems approach to design research processes, methods and approaches implies that we need to further look into and test the different suggested relations between reflection and practice when looking at complex design research that engage in several media and modes of knowledge production.

\section{Conclusions}

Design as a knowledge producing activity is moving forward to develop and better understand the genuine opportunities and perspectives it offers. There is a diverse landscape of possible concepts and positions. The seemingly most potent mode is Research by Design. We need to further define the particularities and draw and develop the landscape of Research by Design. In this paper a possible approach for mapping this landscape has been drafted. Further research and elaboration needs to be carried out. Modelling and methodology building are two important areas for further investigation:

\section{Modelling}

- We have described global models and we have quite a few practice examples.

- We need to build the library of specific perspectives and approaches in design research.

- We need to discuss the theoretical and methodological implications of these perspectives.

- We need to develop further models for theory building: placing Research by Design into a bigger context; the philosophy of practice (phronesis) and science of design.

- We need to relate design research to other concepts from natural sciences, technology research, social sciences, humanities etc.

- We need to transcribe these relations to create relevant proprietary perspectives.

\section{Methodology building}

- Transcribing existing methods and theories from most relevant fields: science and technology studies, natural sciences, grounded theory, action research, network actor theories, ethnographic methods, communication, social theories, media studies, film/video studies, information theory, practice research in other fields etc.

- Developing domain specific methodologies.

- Training the skill to develop project specific methods.

- Building visual analyses and thinking.

- Developing ostensive practices of writing, developing the relation between text and visual material.

- Developing modes of interdisciplinary work across academic disciplines and domains.

Many of these listed tasks and potential developments are already well underway. The main challenge is now to move forward from describing and understanding what is design research towards a position where we start to actively model design research: designing design research.

Knowledge production in practice has far greater potential than being a curious side track in academic research. It is increasingly claiming a more central place in general knowledge production and across domains and in society. It is also about more than just the 
making and tacit knowledge but has great potential to produce the knowledge we need for a sustainable future. The development of one project is illustrative of these activities in knowledge production. Under the construction of the BARELY installation in collaboration with the composer Natasha Barrett and the OCEAN design research network series of concepts emerged (Barrett \& Sevaldson, 2007; Sevaldson, 2008a). They ranged from generalisable experiences of media use in creative processes to the specific answering of the initial research question. The knowledge generated is explicit and generalisable but not in the traditional sense of the scientific experiment. Currently, this project is moving from a basic research mode to applied research, out of the studio, beyond the gallery and out to the field. The project shows a project-specific approach to the relation between practice and reflection. This paper hopefully sketches an approach for such projects. A precondition is to understand the field of design research in general and research by design especially as very rich, complex and multiply layered modes of knowledge production. This poses challenges to the individual design researcher. The hope is that the paper provides a view of how the individual designer researcher can position herself and analyse and develop the relation between the practice and reflection in the individual project.

Drawing the field of design research from a systems perspective is obviously a more than challenging task than can be achieved here. The main point is not to draw a perfect picture but that in opening out for such an approach we may redefine how we conceive our field: it is not in the unity and agreement of a field that its' maturity is shown, but in its' diversity, multiplicity and discourse. It would indeed appear that design research is rapidly maturing.

\section{Acknowledgements}

Thanks to the reviewers who have offered critical and constructive remarks. Thanks to the environment of design researchers at the Oslo School of Architecture, especially Andrew Morrison for patient support. Also thanks to Michael Hensel and my colleagues in the OCEAN design research association who have been an inspiration for many years.

\section{Birger Sevaldson}

Professor, PhD,

Oslo School of Architecture and Design, Institute of Design

Email address: birger.sevaldson@aho.no

\section{References}

Alvesson, M., \& Sköldberg, K. (2000). Reflexive Methodology, New Vistas for Qualitative Research. London: Sage.

American Academy of Family Physicians. (2010). Federation of Practice Based Research Networks. Retrieved 14 September, 2010, from http://www.aafp.org/online/en/home/clinical/research/fpbrn.html

Archer, B. (1995). The Nature of Research. Co-Design, (January), 5-13.

Arnheim, R. (1969). Visual Thinking. Berkley: University of California Press.

Ask, T. (2004). God norsk design: konstituering av industridesign som profesjon. Oslo: Oslo School of Architecture and Design.

Barrett, N., \& Sevaldson, B. (Artist). (2007). Barely [Installation]. 
Barrett, N., \& Sevaldson, B. (2008). BARELY part 2, Retrieved 14 September, 2009, from http://www.oceandesignresearch.net/index.php?option=com_content\&view=article\&id=134\&Itemid=142

Biggs, M. A. R., \& Büchler, D. (2008). Architectural Practice and Academic Reseach. Nordic Journal of Architectural Research, 20(1), 83-92.

Binder, T., \& Brandt, E. (2008). The Design:Lab as platform in participatory design research. CoDesign, 4(2), 115-129.

Binder, T., \& Redstrom, J. (2006). Programs, Experiments and Exemplary Design Research. Paper presented at the Wonderground, Lisboa.

Booth, W. C., Colomb, G. G., \& Williams, J. M. (2008). The Craft of Research. Chicago: University of Chicago Press.

Buchanan, R. (1992). Wicked Problems in Design Thinking. Design Issues, 8(2), 5-21.

Busch, O. v. (2008). FASHION-able: Hacktivism and engaged fashion design. Gothenburg: University of Gothenburg.

Capjon, J. (2004). Trial-and-Error-based innovation. Oslo: AHO.

Checkland, P. (2000). Systems Thinking, Systems Practice. Chichester: John Wiley \& Sons LTD.

Churchman, C. W. (1979). The Systems Approach. Revised and updated. New York: Dell Publishing

Cross, N. (1999). Design Research: A Disciplined Conversation. Design Issues, 15(2), 5-10.

Cross, N. (2007a). Designerly Ways of Knowing. Basel: Birkhäuser.

Cross, N. (2007b). Forty years of design research. Design Studies, 28(1), 1-4.

Csikszentmihalyi, M. (1996). Creativity, Flow and the Psychology of Discovery and Invention. New York: HarperCollins.

Csikszentmihalyi, M. (1999). Implications of a Systems Perspective for the Study of Creativity. In R. J. Sternberg (Ed.), Creativity Handbook. Cambridge: Cambridge University Press.

Design Research Institute RMIT (2009). Retrieved 14 September, 2009, from http://www.rmit.edu.au/research/institutes/design

Dorst, K. (2008). Design research: a revolution-waiting-to-happen. Design Studies, 29(1), 4 -11.

Drucker, J. (2009). Speclab: Digital Aesthetics and Projects in Speculative Computing. Chicago: The University of Chicago Press.

Dunin-Woyseth, H. (2001). Towards a disciplinary identity of the making professions: An introduction. . In H. Dunin-Woyseth \& J. Michl (Eds.), Towards a disciplinary identity of the making professions: the Oslo millennium reader. Research Magazine, 4 (pp. 1-20). Oslo: Oslo School of Architecture and Design.

Dunin-Woyseth, H. (2001). Towards a disciplinary identity of the making professions: An introduction.

Dunin-Woyseth, H. (2005). The "thinkable" and "unthinkable" doctorates: Three perspectives on doctoral scholarship in architecture. In J. Michl \& L. M. Nielsen (Eds.), Building a doctoral programme in architecture and design. Oslo: Oslo School of Architecture and Design.

Dunin-Woyseth, H. (2009). On Designed Knowledge Artefacts. Paper presented at the Communicating (by) Design, Brussels, Sint-Lucas School of Architecture.

Dunin-Woyseth, H., Karlsson, H., Langkilde, K., \& Paavolainen, P. (2007). Kontext - Kvalitet - Kontinuitet: Utvärdering av Vetenskapsrådets anslag till konstnärlig forskning och utveckling 2001-2005. Stockholm: Vetenskapsrådet.

Fallmann, D. (2007). Why Research-oriented Design Isn't Design-Oriented Research: On the tension Between Design and Research in an Implicit Design Discipline. Knowledge, Technology \& Policy, 20, 193-200.

Frayling, C. (1993). Research in Art and Design. London: RCA.

Free University of Bozen-Bolzano. (2007). Research by Design - Research about Design. Retrieved 14 September, 2009, from http://pro.unibz.it/projects/designresearch2007/htm/des_research_projekte_eng.htm 
Friedman, K. (1999, September). Useful and Critical, the Position of Research in Design. Paper presented at the Useful and Critical, Helsinki.

Friedman, K. (2003). Theory construction in design research: criteria: approaches, and methods. Design Studies, $24,507-522$.

Gedenryd, H. (1998). How Designers Work. Unpublished doctoral, Lund University, Lund.

Gibbons, M., Limoges, C., Nowotny, H., Schwartzman, S., Scott, P., \& Trow, M. (1994). The New Production of Knowledge. London: SAGE Publications.

Giere, R. N. (1991). Understanding Scientific Reasoning. Fort Worth: Harcourt Brace Jovanovich

Glanville, R. (1994). A Ship without a Rudder. Retrieved 14 September, 2009, from http://citeseerx.ist.psu.edu/viewdoc/download?doi=10.1.1.37.7453\&rep=rep1\&type=pdf

Glanville, R. (1999). Researching Design and Designing Research. Design Issues, 15(2), 80-91.

Glaser, B. G., \& Strauss, A. (1967). The Discovery of Grounded Theory: Strategies for Qualitative Research. New York: Hawthorne.

Gruber, H. E. (1988). The evolving systems approach to creative work. Creativity Research Journal, 1(1), $27-51$.

Guerin, D., \& Dohr, J. (2009). Part 1: Research-Based Practice. Retrieved 14 September, 2009, from http://www.informedesign.umn.edu/_doc/Research_101_Part_I.pdf

Harvard, Å., Hjelm, S. I., Johanson, U., Niño, A. E., Holm, L. S., Ulmark, P., et al. (Eds.). (2007). Under ytan: En antologi om designforskning. Stockholm: Raster Förlag.

Hatchuel, A., \& Weil, B. (2003). A new approach of innovative design: An introduction to C-K theory. Paper presented at the International Conference of Engineering Design, Stockholm.

Hinte, E. v., \& Tooren, M. v. (2008). First Read This: Systems engineering in practice. Rotterdam: 010 Publishers.

InformeDesign.(2009). What is InformeDesign? Retrieved 14 September, 2009, from http://www.informedesign.umn.edu/

Jonas, W. (2007). Design Research and its Meaning to the Methodological Development of the Discipline. In R. Michel (Ed.), Design Research Now, (pp. 187-206), Basel: Birkhäuser.

Jorgensen, D. L. (1989). Participant Observation. London: Sage Publications.

Koskinen, I., Binder, T., \& Redström, J. (2008). Lab, Field, Gallery, and Beyond. Artifact: Journal of Virtual Design, 2(1), 46-57.

Kottke, T. E. (2008). Optimizing Practice Through Research: A New Perspective to Solve an Old Problem. Annals of Family Medicine, 6, 459-462.

Latour, B. (2005). Reassembling the Social: An Introduction to Actor-Network-Theory. New York: Oxford University Press.

Lawson, B. (1997). How Designers Think: the design process demystified. Oxford: Architectural Press.

Leerberg, T. (2004). Embedded Spaces. Aarhus University, Aarhus.

Lynn, G. (1999). Animate Form. New York: Princeton Architectural Press.

Maier, M. W., \& Rechtin, E. (2000). The Art of Systems Architecture. Boca Raton: CRC Press.

Margolin, V. (Ed.). (1989). Design Discourse: History, Theory, Criticism. Chicago and London: The University of Chicago Press.

Marshall, T., \& Newton, S. (2000). Scholarly design as a paradigm for practice-based research. Working Papers in Art and Design, 1. Retrieved 1 July, 2010 from http://sitem.herts.ac.uk/artdes_research/papers/wpades/vol1/index.html

Mattelmäki, T., \& Mathews, B. (2009). Peeling Apples: Prototyping Design Experiments as Research. Paper presented at the Engaging Artifacts, Oslo School of Architecture and Design.

Mazé, R. (2007). Occupying Time: Design, technology and the form of interaction. Malmö University, Sweden, Malmö. 
Meadows, D. H. (2008). Thinking in Systems. White River Junction: Chelsea Green Publishing.

Michl, J. (2002). On seeing design as redesign: An exploration of a neglected problem in design education. London: Design Addict.

Miller, J. H., \& Page, S. E. (2007). Complex Adaptive Systems: An Introduction to Computational Models of Social Life. Princeton: Princeton University Press.

Morrison, A., Stuedahl, D., Mörtberg, C., Wagner, I., Liestøl, G., \& Bratteteig, T. (2010). Analytical Perspectives. In I. Wagner, T. Bratteteig \& D. Stuedahl (Eds.), Exploring Digital Design: Multidisciplinary design practices. Berlin: Springer.

Nelson, H. G., \& Stolterman, E. (2003). The design way: intentional change in an unpredictable world: foundations and fundamentals of design competence. Englewood Cliffs: Educational Technology.

Niedderer, K., \& Imani, Y. (2008). Developing a Framework for Management: Tacit Knowledge in Research using Knowledge Management Models. Paper presented at the Undisciplined!, 16-19 July, Sheffield.

Nowotny, H. (2004). The Potential of Transdisciplinarity. In H. Dunin-Woyseth \& L. M. Nielsen (Eds.), Discussing transdisciplinarity: Making professions and the new mode of knowledge production (Vol. 6, pp. 10-18). Oslo: Oslo School of Architecture and Design.

Pereira, L. Q. (2000). Alternative Method for Design Activity Research. The Limits for Protocol Analysis. Paper presented at the Design plus Research, 18-20 May, Milan.

Polanyi, M. (1967). The Tacit Dimension. London: Routledge \& Kegan Paul.

Research by design. (2009). Research by design. Retrieved 14 September, 2009, from http://www.researchbydesign.com.au/

Research by design Ltd. (2009). Research by design. Retrieved 14 September, 2009, from http://www.researchbydesign.co.uk/

Rittel, H. W. J., \& Webber, M. M. (1973). Dilemmas in a General Theory of Planning. Policy Sciences, 4, 155169.

RMIT University. (2009). Design Research Institute. Retrieved 14 September, 2009, from http://www.rmit.edu.au/research/institutes/design

Robson, C. (1993). Real World Research. Oxford: Blackwell.

Rust, C., Mottram, J., \& Till, J. (2007). AHRC Research Review, Practice-Led Research in Art, Design and Architecture. Shefield: Arts \& Humanities Research Council.

Schön, D. A. (1982). The Reflective Practitioner. London: Basic Books.

Scrivener, S. (2000). Reflection in and on action and practice in creative-production doctoral projects in art and design. Working papers in Art \& Design, 1. Retrieved 14 September, 2009, from http://sitem.herts.ac.uk/artdes_research/papers/wpades/vol1/scrivener2.html

Scrivener, S. (2004). The practical implications of applying a theory of practice based research: a case study. Working Papers in Art and Design, 3. Retrieved 14 September, 2009, from http://sitem.herts.ac.uk/artdes_research/papers/wpades/vol3/ssabs.html

Sevaldson, B. (1999). Research Design in Design Research. Paper presented at the Cumulus Conference, 12-16 April, Rome.

Sevaldson, B. (2000). The Integrated Conglomerate Approach: A Suggestion for a Generic Model of Design Research. In D. Durling \& K. Friedman (Eds.), Proceedings of the conference Doctoral Education in Design: Foundations for the Future, held 8-12 July 2000, La Clusaz, France (pp. 163-170). Stoke-onTrent: Staffordshire University Press.

Sevaldson, B. (2001). Designing Time (Vol. 2001). Retrieved 14 September, 2009, from http://www.birgersevaldson.no/Konseptdesign2001/index.html.

Sevaldson, B. (2004a). Designing Time: A Laboratory for Time Based Design. Paper presented at the Future Ground, 17-21 November, Melbourne.

Sevaldson, B. (2004b). Ways of Working. Paper presented at the Digitale Designprodukter - vision og virkelighed , 8 - 9 January, Kolding, Denmark. 
Sevaldson, B. (2005). Developing Digital Design Techniques. Oslo: Oslo School of Architecture and Design.

Sevaldson, B. (2008a). Rich Research Space. FORMakademisk, 1(1), 28-44. Retrieved 14 September, 2009, from http://www.formakademisk.org/index.php/formakademisk/article/view/17/12

Sevaldson, B. (2008b). A System Approach to Design Learning. In A. Menges (Ed.), Systemisches Denken und Integrales Entwerfen / System thinking and Integral Design (pp. 22-33). Offenbach: Präsident der Hochschule für Gestaltung Offenbach am Main.

Sevaldson, B. (2009). Systems Oriented Design. Retrieved 14 September, 2009, from http://www.systemsorienteddesign.net

Sint-Lucas School of Architecture. (2009). About the RTS Program. Retrieved 14 September, 2009, from http://rts.bydesigning.info/rts/

Sternberg, R. J., \& Lubart, T. I. (1999). The Concepts of Creativity: Prospects and Paradigms. In R. J. Sternberg (Ed.), Handbook of Creativity. Cambridge: Cambridge University Press.

Stringer, E. (1996). Action Research: A Handbook for Practitioners. Thousand Oaks: Sage.

Swann, C. (1999, September). Translating action research into design practice. Paper presented at the Useful and critical, Helsinki.

Tevino, L. K., Lengel, R. H., Bodensteiner, W., Gerloff, E. A., \& Muir, N. K. (1990). The Richness Imperative and Cognitive Style: The Role of Individual Differences in Media Choice Behaviour. Management Community Quarterly, 4(2), 176 - 197.

Yin, R. K. (1994). Case Study Research: Design and Methods. Thousand Oaks: Sage. 